\title{
Cervical Endometrioid Adenocarcinoma
}

National Cancer Institute

\section{Source}

National Cancer Institute. Cervical Endometrioid Adenocarcinoma. NCI Thesaurus. Code C6343.

A cervical adenocarcinoma with the histologic characteristics of the endometrioid adenocarcinoma of the endometrium. 